\title{
Energy analysis in ice hockey arenas and analytical formula for the temperature profile in the ice pad with transient boundary conditions
}

\author{
Andrea Ferrantelli ${ }^{\mathrm{a}}$, Klaus Viljanen ${ }^{\mathrm{b}}$ and Jarek Kurnitski ${ }^{\mathrm{a}} \mathrm{b}$ \\ ${ }^{a}$ Tallinn University of Technology, Department of Civil Engineering and Architecture, 19086 \\ Tallinn, Estonia; ${ }^{b}$ Aalto University, Department of Civil Engineering, P.O.Box 12100, 00076 \\ Aalto, Finland
}

\section{ARTICLE HISTORY \\ Compiled March 9, 2019}

\begin{abstract}
The energy efficiency of ice hockey arenas is a central concern for the administrations, as these buildings are well known to consume a large amount of energy. Since they are composite, complex systems, solutions to such a problem can be approached from many different areas, from managerial to technological to more strictly physical.

In this paper we consider heat transfer processes in an ice hockey hall, during operating conditions, with a bottom-up approach based upon on-site measurements. Detailed heat flux, relative humidity and temperature data for the ice pad and the indoor air are used for a heat balance calculation in the steady-state regime, which quantifies the impact of each single heat source. We then solve the heat conduction equation for the ice pad in transient regime, and obtain a generic analytical formula for the temperature profile that can be used in practical applications.

We then apply this formula to the resurfacing process for validation, and find good agreement with an analogous numerical solution. Since it is given with implicit initial condition and boundary conditions, it can be used not only in ice hockey halls, but in a large variety of engineering applications.
\end{abstract}

\section{KEYWORDS}

transient heat conduction; cooling; theoretical models; analytical solutions; ice rinks; energy efficiency

\section{Introduction}

Ice hockey arenas are fairly energy demanding systems, consuming a very large amount of energy that approaches $\sim 1800 \mathrm{MWh}$ per year. In particular, according to several studies (see e.g. Karampour (2011); Räikkönen (2012); Ferrantelli et al. (2013)) refrigeration is responsible for nearly 43 percent of the total energy consumption of the ice hockey hall. Process optimization and energy efficiency have therefore increased their role of key research concepts on very diverse, yet correlated aspects of energy management. These can range from the design of the concrete pad as in Haghighi et al. (2014) to the air distribution and ventilation (Yang et al. $(2000,2001)$ ) and their effect on 
the overall heat balance, as addressed by Palmowska and Lipska (2018); Toomla et al. (2018); Taebnia et al. (2019), as well as the exergoeconomic analysis performed by Erol et al. (2017).

Furthermore, these types of buildings constitute a challenging setup for studies in building physics, due to the diverse physical processes often concurring to each other, which take place in the environment. For instance, ventilation and air conditioning in such large and complex systems are an intriguing field of study, as illustrated by Caliskan and Hepbasli (2010); Daoud et al. (2008); Teyssedou et al. (2013).

The various contributions to the energy balance in such a complex system are usually addressed numerically. Heat and mass transfer processes occur both above and inside the large ice/concrete slab forming the ice rink, and have been thoroughly studied for at least a couple of decades now, see for instance Negiz et al. (1993); Hastaoglu et al. (1995) and more recently Teyssedou et al. (2009). As an example, Computational Fluid Dynamics (CFD) simulations in 2D were performed under steady state conditions in Bellache et al. (2005), where velocity, temperature and absolute humidity distributions were predicted for an indoor ice rink with heating provided by ventilation. The numerical model was then extended to transient processes by the same authors in Bellache et al. (2006), adding calculations of heat transfer through the ground, energy gains from lights and resurfacing effects. A CFD numerical analysis of the radiative component induced by thermostatically controlled radiant heaters has been considered in Omri et al. (2016), tracking the heat flow and temperature inside the ice hall, together with the heat fluxes into the ice pad.

Regarding analytical solutions, the literature is far less abundant mostly because of evident technical difficulties. General solutions for coupled heat transfer do exist however, since they pertain more general cases such as building foundations and radiant floors. Somrani et al. (2008) used the Interzone Temperature Profile Estimation (ITPE) method developed in Krarti (1999), considering an ice pad with constant upper boundary condition (the air temperature just above the ice surface), laying over sand, insulation, a soil layer with time-varying temperature and a water table with constant temperature.

More recent investigations concentrate on large scales, and consider the entire ice hall in view of numerical integration towards energy optimization, see for instance Mun and Krarti (2011). As an example, Tutumlu et al. (2018) formulated a model for assessing the thermal performance of a cooling system consisting of an ice rink, a chiller unit and a spherical thermal energy storage tank. Computing the ice rink heat gain and the energy consumption of the chiller unit, they were able to determine the operation time of this large system in function of indoor conditions, storage tank and chiller characteristics.

Unfortunately, heat flux data during the ice pad resurfacing, which constitutes the more energy consuming event in the entire operative cycle, are still missing from the literature. Additionally, in this specific context there currently exists a lack of heat transfer formulas which are easy to apply to practical design problems.

In this paper we try to address these issues by considering the topic on a smaller scale, i.e. an ice pad element, by means of a bottom-up approach based on measurements. For the first time in the literature, we report detailed measurements of the heat flux as well as ice temperature at the surface and at the bottom of the ice pad during resurfacing. These constitute the time-dependent boundary conditions (b.c.) for an analytical temperature profile along the ice slab depth which we accordingly compute.

Though the derivation is rather involved, we recast the resulting temperature profile in function of the boundary conditions as a simple formula which can be easily im- 
plemented in common computational software. This is another novelty of this paper, aimed at immediate practical usage. Our main purpose is indeed to provide a concise reference for practical applications in ice hockey halls, by means of an easily applicable formula for the ice pad temperature together with comprehensive data of heat flux, air stratification and humidity at various heights in the ice hockey arena.

We choose the resurfacing stages because they are the most complex and energy consuming phases of the operational cycle of an ice hockey hall, due to the large amount of heat transferred to the ice pad in a relatively short time. This affects importantly the efficiency and energy consumption of the refrigerating system, and here we aim at finding applicable quantitative knowledge to aid e.g. system control and space heating investigations.

Though obtained for a specific case-study, our measurements can be applied to the majority of standard ice hockey halls, for instance in the development of new control methods for ice rink cooling systems (see for instance Lü et al. (2014, 2015)). Our findings also help in developing methods to reduce the indoor temperature stratification as suggested by Taebnia et al. (2019), or to collect a portion of the heat generated and reuse it in the ice hockey hall. Moreover, the temperature profile formula we obtain is very general and is not limited to ice hockey arenas; rather, it can be applied to other heat conduction processes with transient boundary conditions.

The present paper is organized as follows: Section 2 reports the experimental setup and measurements, as well as an energy balance analysis which is validated with experimental data. We examine the heat flux on the ice pad, the indoor air relative humidity $(\mathrm{RH})$ in its proximity and the temperatures at surface and at the ice/concrete interface during a typical day of operation.

In Section 3 we use the field measurements to estimate the diverse contributions to the heat load over the ice pad in the steady state conditions immediately preceding the resurfacing, considering convection, condensation and radiation. An analytical formula for the ice pad temperature in transient conditions is then derived in Section 4. Our results are summarized and further discussed in the Conclusions, and finally in Appendix A we apply our formula to the calculation of the temperature profile inside the ice pad during resurfacing, validating it with the initial data.

\section{Ice hockey hall and temperature measurements}

Good skating conditions occur when the ice surface is smooth, hard and slippery enough. Usually the ice temperature at the surface is between $-3^{\circ} \mathrm{C}$ and $-5^{\circ} \mathrm{C}$. In any cases the temperature of the ice should be kept under $-1^{\circ} \mathrm{C}$ to maintain ice hardness, as explained in Poirier et al. (2011). To keep the ice smooth and in optimal conditions after the wear due to skating, it is necessary to perform periodical maintenance, which is usually done by means of resurfacing machines. These devices first shave the ice, then brush it and eventually spread a thin layer of new water on the surface.

At each maintenance cycle, 300 to 800 liters of water are used, corresponding to a $0.25-0.5 \mathrm{~mm}$ thick water layer. The water cooling and freezing processes generate a sudden increase in the ice temperature, which lowers the cooling efficiency of the refrigerating system, thus increasing the operational costs of the ice hall. Accurate analysis of this phenomenon is then important to optimize the refrigeration process and to achieve overall energy saving.

The field study discussed in this paper was carried out at the Reebok Arena in 


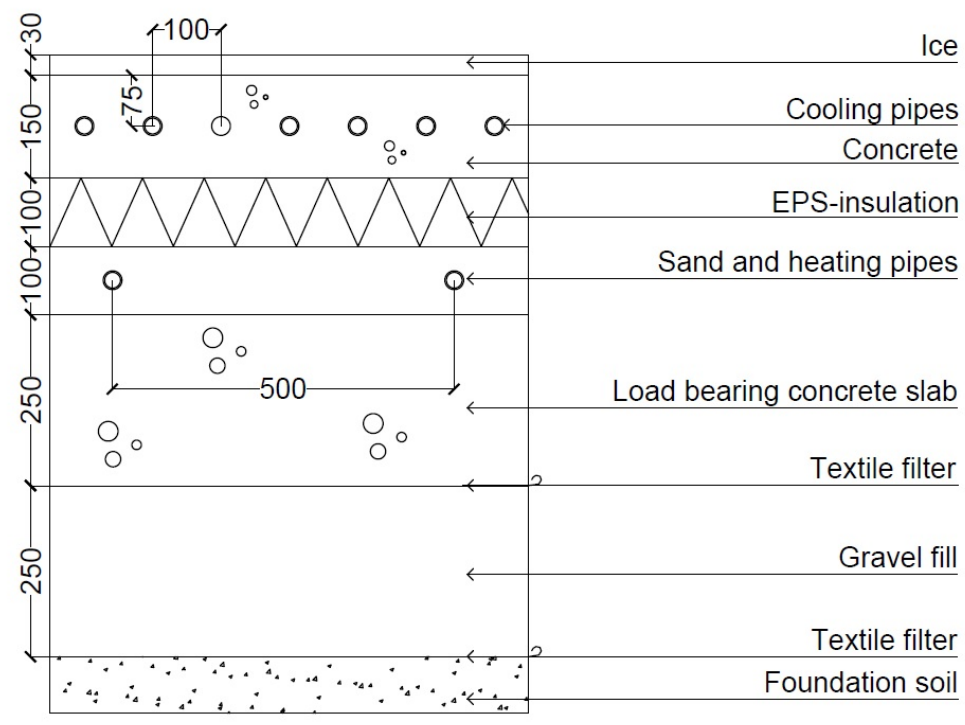

Figure 1. A portion of the ice rink floor structure considered.

Leppävaara, Finland, during summer conditions ${ }^{1}$. The ice hall has two identical ice rinks of size $1624 \mathrm{~m} 2$ each. There are no major stands in the hall and the ventilation air flow rate varies between $3-6 \mathrm{~m} 3 / \mathrm{s}$ during the year. The refrigeration system is indirect, with ammonium as the refrigerant and ethylene glycol as the brine.

Consider now a modular component of the ice/concrete slab as in Fig.1: ice 30mm, concrete slab $150 \mathrm{~mm}$ with brine pipes at the middle, EPS-insulation $100 \mathrm{~mm}$, sand $100 \mathrm{~mm}$ with frost pipes and a load bearing concrete slab $250 \mathrm{~mm}$. The coefficient of performance for the refrigeration system is $\sim 1.6$ on the average, as documented in Ferrantelli et al. (2013).

We focus on the first resurfacing process in Fig.2, corresponding to the peak near 12:45. The ice surface has an initial surface temperature $T_{S} \sim-4.5^{\circ} \mathrm{C}$, the whole ice pad is at $-5^{\circ} \mathrm{C}$ on the average. During resurfacing, $m_{w}=450 \mathrm{~kg}$ of water at temperature $T_{w}=40^{\circ} \mathrm{C}$ are spread on the ice surface at $t=0 \mathrm{~s}$. The entire process consists of three phases:

1. cooling of the water layer by contact with the ice pad, convection and radiation with the surroundings,

2. complete freezing of the water by the same processes,

3. cooling of the new ice from $T_{\text {freeze }}=0^{\circ} \mathrm{C}$ to $T_{3} \sim-4^{\circ} \mathrm{C}$ (see Fig.3). A thermal camera records the surface temperature point wise, taking pictures at intervals $\Delta t=10 \mathrm{~s}$. Moreover, heat flux and temperature are measured with a heat flux plate and a pt-100 temperature sensor installed at the ice/concrete interface in the slab, as shown in Fig.2. The according data are plotted in Fig.3.

The physical properties of water are evaluated at the film temperature $T_{f}=20^{\circ} \mathrm{C}$. This implies the specific heat $c_{p, w}=4.182 \mathrm{~kJ} / \mathrm{kgK}$. Since $m_{w}=450 \mathrm{~kg}$ of water are spread on the ice, the average thickness is only

$$
x=\frac{m_{w}}{\rho A}=0.28 \mathrm{~mm},
$$

\footnotetext{
${ }^{1}$ Toomla et al. (2018) have performed an extended study in a different ice hockey arena.
} 


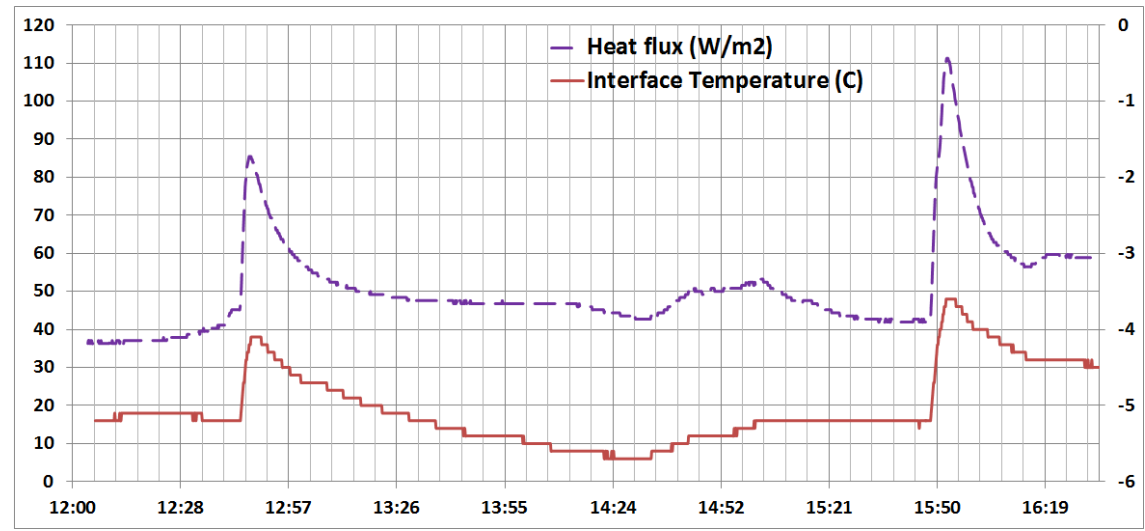

Figure 2. Measurements of temperature and heat flux at the ice/concrete interface.

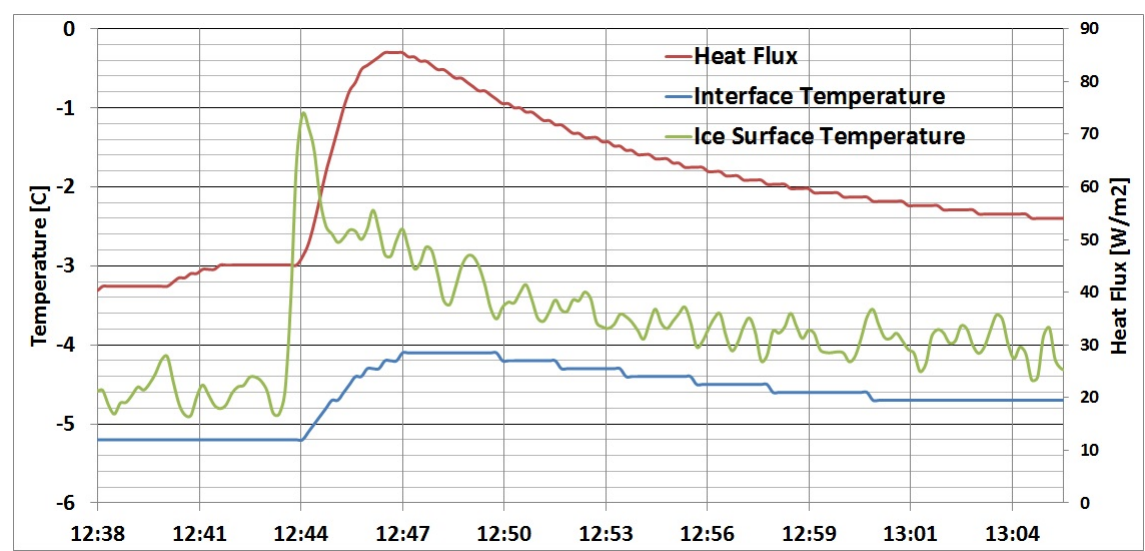

Figure 3. Heat flux and temperatures during the water chilling and freezing.

which is anyway just an indicative value, as the precision of the resurfacing machine is not high enough. The size of the ice rink is $A=1624 \mathrm{~m} 2, h_{f s}=338 \mathrm{~kJ} / \mathrm{kg}$ is the water latent heat of freezing and $c_{p, i}=2.05 \mathrm{~kJ} / \mathrm{kgK}$ is the specific heat of ice at $T \sim 0^{\circ} \mathrm{C}$. The water chilling and freezing loads are thus obtained as follows,

$$
\begin{aligned}
& Q_{w}=\left[m_{w}\left[h_{f s}+c_{p, w}\left(T_{w}-0\right)+c_{p, i}\left(0-T_{i c e}\right)\right]\right] \\
& =231.21 M J ; q_{w}=142.37 \frac{k J}{m^{2}}, \\
& Q_{1}=m_{w} c_{p, w}\left(T_{w}-0\right)=75.28 M J ; \quad q_{1}=\frac{Q_{1}}{A}=46.4 \frac{k J}{m^{2}}, \\
& Q_{2}=h_{f s} m_{w}=152.1 M J ; \quad q_{2}=\frac{Q_{2}}{A}=93.7 \frac{k J}{m^{2}}, \\
& Q_{3}=m_{w} c_{p, i}\left(0-T_{i c e}\right)=3.69 M J ; \quad q_{3}=\frac{Q_{3}}{A}=2.27 \frac{\mathrm{kJ}}{\mathrm{m}^{2}}
\end{aligned}
$$

where $T_{i c e}$ is the temperature of the frozen resurfacing water under the new steady state conditions. The theoretical heat load Eq.(3) is consistent with the literature, as in Seghouani et al. (2009, 2011).

Let us verify immediately that the theoretical heat flux in (3) is consistent with the measurements at the ice/concrete interface in Fig.3. The integral of the heat flux curve 
is the total heat transferred during the resurfacing, to be compared with Eq.(3). For better precision, we split the curve into three contributions: two polynomials plotted in Fig. 4 and Fig.5, and a constant value $\dot{q}_{\max }=85.4839 \mathrm{~W} / \mathrm{m} 2$, corresponding to the narrow $(\Delta t \sim 30 \mathrm{~s})$ plateau at the top of the curve in Fig.3.

If $\dot{q}_{A}$ is the heat flux rate for the first contribution and $\dot{q}_{B}$ the flux for the second curve, we obtain the following expressions:

$$
\begin{aligned}
& \dot{q}_{A}(t)=3 \times 10^{-7} t^{4}-10^{-4} t^{3}+0.0106 t^{2}+0.0414 t+45.191 \\
& \dot{q}_{B}(t)=3 \times 10^{-12} t^{4}-2 \times 10^{-8} t^{3}+5 \times 10^{-5} t^{2}-0.0647 t+85.873 .
\end{aligned}
$$

Integrating the above over the respective time intervals gives

$$
\begin{aligned}
q_{A} & =\int_{0}^{140} \dot{q}_{A}(t) d t=10.05 \frac{k J}{\mathrm{~m}^{2}}, \\
q_{B} & =\int_{0}^{2300} \dot{q}_{B}(t) d t=127.88 \frac{\mathrm{kJ}}{\mathrm{m}^{2}},
\end{aligned}
$$

to which we add the heat transferred at the peak, namely

$$
q_{\max }=85.4839 \frac{W}{m^{2}} \times \Delta t[s]=2.57 \frac{k J}{m^{2}} .
$$

Thus the total heat transferred to the ice pad during the three phases of resurfacing in Eq.(3) is measured as

$$
q_{\exp }=140.49 \frac{k J}{m^{2}}
$$

This is very close to the theoretical mean value in Eq.(3), namely

$$
q_{w}=142.37 \frac{k J}{m^{2}}
$$

we find indeed

$$
\Delta q \equiv q_{w}-q_{\exp }=1.88 \frac{k J}{m^{2}}, \quad \%(\Delta q)=1.32 \%,
$$

which is fairly satisfactory and verifies the consistency of the theoretical and measured heat load ${ }^{2}$.

\subsection{Indoor air measurements}

Regarding the air temperature and $\mathrm{RH}$, we used different sets of data obtained in different sessions. One set of data was obtained at $0.04 \mathrm{~m}, 0.1 \mathrm{~m}$ and $0.24 \mathrm{~m}$ above the ice rink with accuracy $\pm 2 \%$ for $0-90 \%$ relative humidity and $\pm 3 \%$ for $90-100 \%$ $\mathrm{RH}$. The accuracy of the temperature measurement was $\pm 0.4^{\circ} \mathrm{C}$. Later on, additional measurements were made at $0.6 \mathrm{~m}, 1.2 \mathrm{~m}, 1.8 \mathrm{~m}$ and $2.2 \mathrm{~m}$ above the ice with PT-100

\footnotetext{
${ }^{2}$ This is precise enough for our purposes, notice anyway that one has some freedom in setting the upper limit of integration in (10). The order of magnitude is anyway what matters.
} 


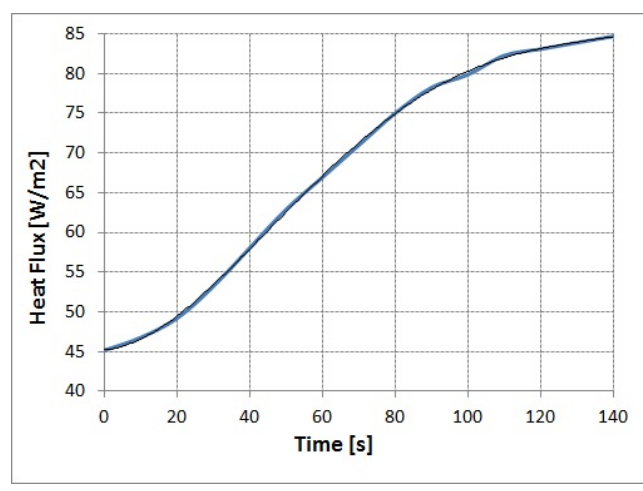

Figure 4. Interpolation curve for Eq.(9).

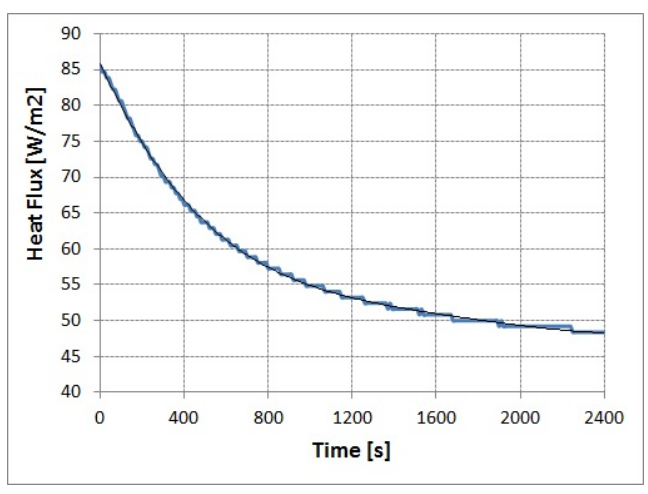

Figure 5. Interpolation curve for Eq.(10).

temperature sensors, with accuracy $\pm 0.5^{\circ} \mathrm{C}$. Moreover, the temperature was measured at $5.0 \mathrm{~m}$ and $8.3 \mathrm{~m}$ height with an accuracy of $\pm 0.5^{\circ} \mathrm{C}$. All measurements were done with $\Delta t=10$ s interval and lasted approximately four hours. The probes set at $0.04-$ $2.2 \mathrm{~m}$ height were set up in a metal holder standing above the ice; this was located at one corner of the ice rink, $1 \mathrm{~m}$ from the edge of the ice pad.

Further measurements were later performed at $0.005 \mathrm{~m}, 0.01 \mathrm{~m}, 0.04 \mathrm{~m}, 0.1 \mathrm{~m}, 0.24 \mathrm{~m}$ and $5 \mathrm{~m}$ height over the ice. The accuracy of relative humidity of the probe was the same as before, while for temperature measurements the accuracy was $\pm 0.3^{\circ} \mathrm{C}$. All data were collected at one instance after the sensors had became steady. The probes at $0.005-0.24 \mathrm{~m}$ height were again set up in a metal holder over the ice. Two locations of the holder were used, at the corner of the ice rink and close to the centre of the ice pad, at approximately $8 \mathrm{~m}$ from the edge.

The air temperature at $0.6 \mathrm{~m}-8.3 \mathrm{~m}$ over the ice is plotted in Fig.6, while that at $0.04 \mathrm{~m}-0.24 \mathrm{~m}$ in Fig.7. All the other data are shown in Table 1.

The plots show that, as expected, the air temperature above the ice rink is strongly stratified, see Fig.6, Fig.7 and Table 1, consistently with Toomla et al. (2018). The temperature at $0.6 \mathrm{~m}$ height is $2^{\circ} \mathrm{C}$ and $10^{\circ} \mathrm{C}$ at $5 \mathrm{~m}$. Interestingly, by virtue of the mixing effect of the ventilation system supplying warm air at $25^{\circ} \mathrm{C}$ at $5 \mathrm{~m}$ above the ice, the highest temperature is at $5 \mathrm{~m}$ instead of $8.3 \mathrm{~m}$ (Fig.6). Furthermore, the stratified air temperature at $0.6-2.2 \mathrm{~m}$ turns into a more uniform temperature when the skaters enter the ice rink at 14:30 and start mixing the air layers.

The measured relative humidity $(\mathrm{RH})$ and absolute humidity $(\mathrm{AH})$, listed in Table 1 , suggest that above the ice rinks the $\mathrm{RH}$ is uniform at heights $0.005 \mathrm{~m}-0.24 \mathrm{~m}$ over the ice and distinctly lower farther from the ice pad. The relative humidity is higher above the ice than in the other parts of the space, yet it never reaches $95-100 \%$.

The measurements did not imply any significant differences in temperature or relative humidity depending on the location over the ice pad, either corner or centre, in agreement with Taebnia et al. (2019). 


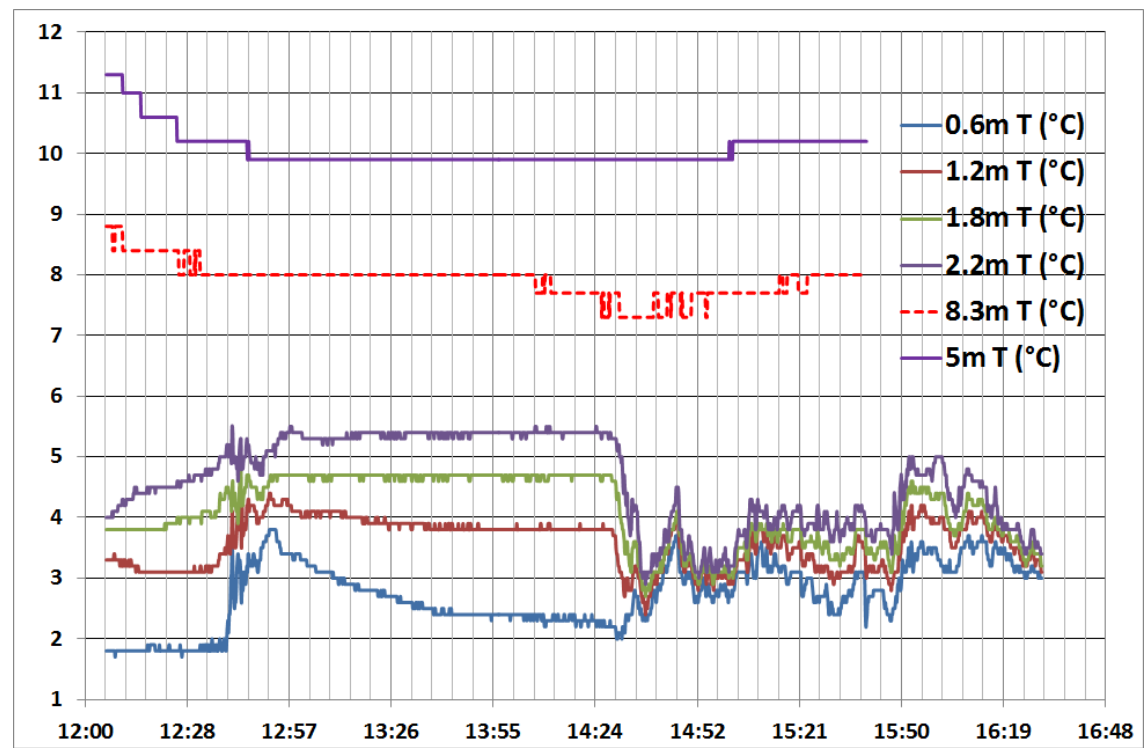

Figure 6. Air temperature above the ice during resurfacing and skaters activity.

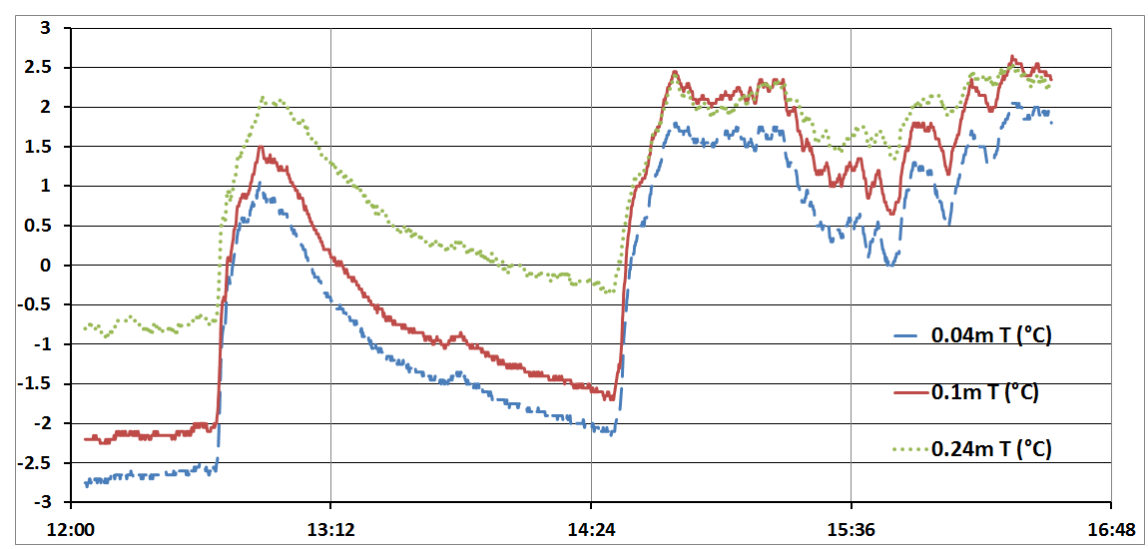

Figure 7. Air temperature above the ice rink at different heights, closer to the ice.

Table 1. Air temperature, relative humidity $(\mathrm{RH})$ and absolute humidity $(\mathrm{AH})$ as measured at different heights from the ice pad surface.

\begin{tabular}{lccc}
\hline Height over the ice $[\mathrm{m}]$ & $\mathrm{T}\left[{ }^{\circ} \mathrm{C}\right]$ & $\mathrm{RH}[\%]$ & $\mathrm{AH}[\mathrm{g} / \mathrm{m} 3]$ \\
\hline 5.0 & 4.2 & 77.2 & 5.0 \\
0.24 & -0.8 & 90.2 & 4.1 \\
0.1 & -2.2 & 89.6 & 3.7 \\
0.04 & -2.7 & 89.3 & 3.5 \\
0.01 & -3.1 & 88.1 & 3.3 \\
0.005 & -3.5 & 88.2 & 3.2 \\
\hline
\end{tabular}




\section{Energy balance and ice temperatures before resurfacing}

In this section we use the field measurements to compute some estimates of the heat loads on the ice pad before resurfacing. We consider convection, condensation and radiation. In this case the heat transfer is steady state in good approximation, so this is easy to accomplish. Even though it is difficult to obtain very precise values, this shows well the various factors concurring to the overall energy balance on the ice hockey rink.

Consider first Fig.2 and Fig.3 before resurfacing, namely before 12:43. The heat flux through the ice pad and the ice temperature, both measured at the ice/concrete interface, are respectively $\dot{q}=41.85 \mathrm{~W} / \mathrm{m} 2$ (average) and $T_{I}=-5.2^{\circ} \mathrm{C}$. The ice pad thickness is on the average $L=30 \mathrm{~mm}$. We can derive the ice temperature at surface very easily, if $k_{i c e}=2.25 \mathrm{~W} / \mathrm{mK}$,

$$
T_{S}=T_{I}+\frac{L}{k_{i c e}} \dot{q}=-4.64 C,
$$

which is consistent with the ice surface temperature given in Fig.3.

The heat flux on the ice track surface is the sum of several contributions,

$$
\begin{aligned}
& \dot{q}=\dot{q}_{\text {rad }}+\dot{q}_{c o n v}+\dot{q}_{\text {wvcond }}+\dot{q}_{\text {lamp }} \\
& =h_{\text {rad }}\left(T_{\text {ceiling }}-T_{S}\right)+\left(h_{\text {conv }}+h_{\text {wvcond }}\right)\left(T_{\text {in }}-T_{S}\right)+\dot{q}_{\text {lamp }},
\end{aligned}
$$

namely thermal radiation from the ceiling, convection and water vapor condensation at the surface, and heat load from the lighting system. For simplicity, we neglect the thermal radiation from the vertical walls and from the audience stands (they do not give a relevant contribution anyway).

For convection we use $T_{i n}=T(0.04 \mathrm{~m})=-3.5^{\circ} \mathrm{C}$, see Table 1 . Thus the heat transfer coefficient takes into account both natural convection and a correction given by forced convection, following ASHRAE (2010)

$$
h_{\text {conv }}=3.41+3.55 \mathrm{~V}=3.94 \frac{W}{m^{2} K},
$$

corresponding to $V=0.15 \mathrm{~m} / \mathrm{s}$ for the air flow right on top of the ice, specifically at the height $4 \mathrm{~cm}$, as stated above. The convection heat flow is therefore

$$
\dot{q}_{\text {conv }}=h_{\text {conv }}\left(T_{i n}-T_{S}\right)=4.49 \frac{W}{m^{2}} .
$$

The radiation heat transfer coefficient is written instead as

$$
h_{\text {rad }}=\varepsilon_{12} \sigma\left(T_{\text {ceiling }}^{2}+T_{\text {ice.sur }}^{2}\right)\left(T_{\text {ceiling }}+T_{S}\right)=1.39 \frac{W}{m^{2} K},
$$

where $T_{\text {ceiling }}=18^{\circ} \mathrm{C}$ and the resulting emissivity is computed according to ASHRAE (1994),

$$
\varepsilon_{12}=\left[\frac{1}{F_{c i}}+\left(\frac{1}{\varepsilon_{\text {ceiling }}}-1\right)+\frac{A_{c}}{A_{i}}\left(\frac{1}{\varepsilon_{\text {ice.sur }}}-1\right)\right]^{-1}
$$

The view factor is $F_{c i}=0.68$, and emissivities $\varepsilon_{i c e . s u r}=0.98$ and $\varepsilon_{\text {ceiling }}=0.28$ for the 
ice surface and the ceiling (a load bearing sheet of galvanized steel) are respectively used Räikkönen (2012). These give $\varepsilon_{12}=0.28$.

One must also take into account the radiative heat transferred to the ice pad by the lighting system. The lamps in Leppävaara are metal halide, which implies a contribution of $400 \mathrm{~W}$ per lamp. The portion of this power that is turned into heat is nearly $62 \%$, as given by the manufacturer Osram GmbH (2014). Using the upper limit for the heat generation for 40 lamps gives the following contribution:

$$
\dot{Q}_{l a m p}=9.92 \mathrm{~kW}
$$

corresponding to the following heat flux,

$$
\dot{q}_{l a m p}=\frac{\dot{Q}_{l a m p}}{A}=6.11 \frac{W}{m^{2}} .
$$

The water vapor condensation heat load is computed following Granryd (2005),

$$
\dot{q}_{\text {wvcond }}=h_{d}\left(T_{i n}-T_{S}\right) \quad\left[\frac{W}{m^{2}}\right]
$$

where the heat transfer coefficient for condensation $h_{d}$ is calculated from

$$
\begin{aligned}
h_{d} & =1750 h_{\text {conv }} \frac{\Delta p}{\Delta T}, \quad[p]=[a t m] \\
\Delta p & =\varphi_{i n} p_{i n}-p_{s} .
\end{aligned}
$$

Here $\Delta T=T_{i n}-T_{S}$, and $\varphi_{\text {in }}=0.88$ is the relative humidity at $4 \mathrm{~cm}$ from the ice surface, as in Table 1 . The saturation pressures are calculated from (here $[\mathrm{T}]=[\mathrm{C}]$ )

$$
\begin{aligned}
& p_{\text {in }}=10^{5} \exp \left(17.391-\frac{6142.83}{273.15+T_{\text {in }}}\right), \\
& p_{s}=10^{5} \exp \left(17.391-\frac{6142.83}{273.15+T_{S}}\right) .
\end{aligned}
$$

We thus obtain $h_{d}=0.9 \mathrm{~W} / \mathrm{m}^{2} \mathrm{~K}$ and $\dot{q}_{\text {wvcond }}=1.03 \mathrm{~W} / \mathrm{m}^{2}$. By substituting this result into (16), together with Eqs.(18), (19) and (20), and adding also (22), we get

$$
\dot{q}=\dot{q}_{r a d}+\dot{q}_{c o n v}+\dot{q}_{w v c o n d}+\dot{q}_{l a m p}=31.25+4.49+1.03+6.11=42.87 \frac{\mathrm{W}}{\mathrm{m}^{2}},
$$

that overestimates only slightly the measured value $41.85 \mathrm{~W} / \mathrm{m}^{2}$. The percentage of each contribution is listed in Fig.8. Now we focus on the ice/concrete pad and consider only conduction. The steady-state conditions provide for the heat flow inside the slab

$$
\dot{q}=\frac{T_{S}-T_{p}}{R_{t o t}}=\frac{T_{S}-T_{p}}{R_{\text {ice }}+R_{\text {conc }}},
$$

where $T_{p}$ is the temperature at the top of the pipes and the thermal resistances of the 


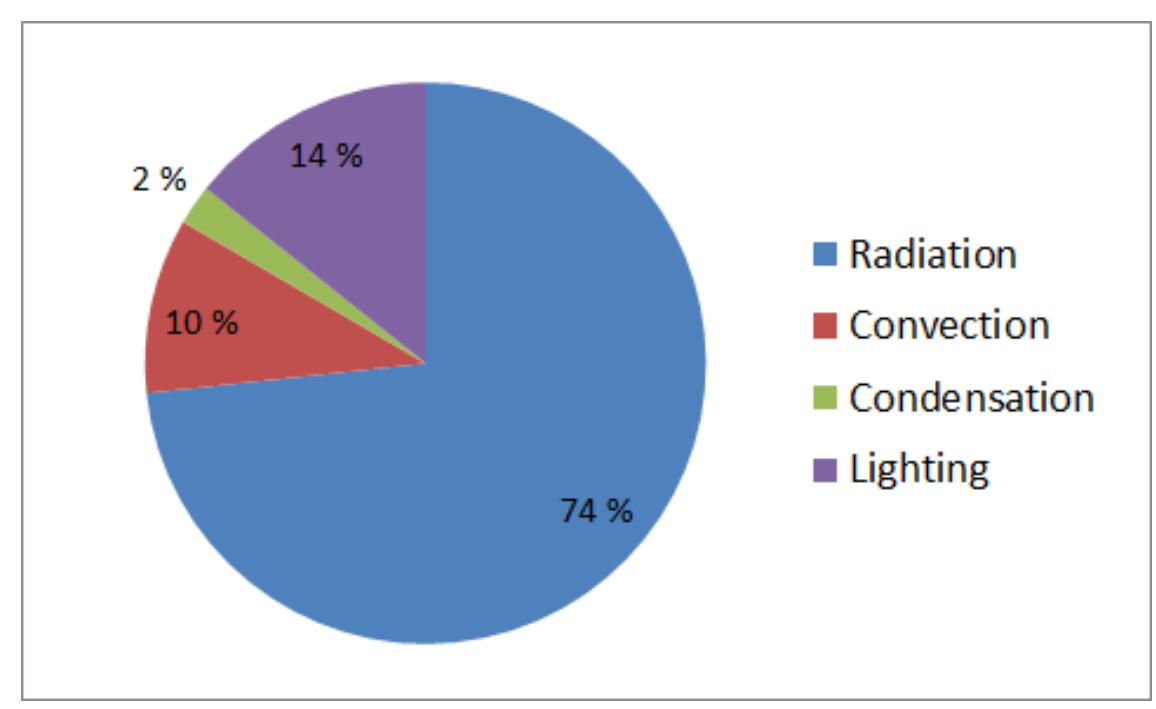

Figure 8. Contributions to the heat load over the ice pad in steady state conditions, Eq(27).

ice and concrete slabs are written as

$$
\begin{aligned}
& R_{\text {ice }}=\frac{L}{k_{\text {ice }}}=1.33 \times 10^{-2} \frac{\mathrm{Km}^{2}}{W}, \\
& R_{\text {conc }}=\frac{d}{k_{\text {conc }}}=1.67 \times 10^{-2} \frac{\mathrm{Km}^{2}}{W},
\end{aligned}
$$

where $k_{i c e}=2.25 \mathrm{~W} / \mathrm{mK}$ and $k_{\text {conc }}=1.8 \mathrm{~W} / \mathrm{mK}$. The temperature at the top of the pipes $T_{p}$ is then estimated from

$$
\dot{q}=41.85 \mathrm{~W} / \mathrm{m}^{2}=\frac{T_{S}-T_{p}}{R_{t o t}}
$$

which gives $T_{p}=-5.9^{\circ} \mathrm{C}$ and can be cross-checked with heat balance inside the concrete slab only,

$$
\dot{q}=\frac{T_{I}-T_{p}}{R_{\text {conc }}}
$$

This in fact returns $\dot{q}=41.92 \mathrm{~W} / \mathrm{m}^{2} \approx 41.85 \mathrm{~W} / \mathrm{m}^{2}$.

Let us finally check the agreement between the thermal camera measurement and the result (15) for the ice surface temperature. The heat transfer via conduction inside the ice pad is written as

$$
\dot{q}_{I}=\frac{T_{S}-T_{I}}{R_{\text {ice }}}
$$

Since this also must be equal to $\dot{q}$, namely $\dot{q}_{I}=\dot{q}=41.85 \mathrm{~W} / \mathrm{m} 2$ because of the steady state conditions, substituting and solving with respect to the temperature at the ice/concrete interface we get

$$
T_{I}=T_{S}-R_{i c e} \dot{q}=-5.2 C,
$$


that is consistent with the measured value indeed.

\section{Analytical temperature profile for the ice pad}

In this section we derive an analytical formula for the temperature profile of the ice pad $T_{i c e}(t, x)$, which can be used under any specific situation occurring in the ice hockey hall. The problem consists of solving the heat equation

$$
\frac{\partial u}{\partial t}=\alpha_{I} \frac{\partial^{2} u}{\partial x^{2}}
$$

where $0<x<L=30 \mathrm{~mm}$, and $\alpha_{I}$ is the thermal diffusivity of ice, with the timedependent boundary conditions

$$
\begin{aligned}
& u(0, t)=T_{S}(t), \\
& u(L, t)=T_{I}(t),
\end{aligned}
$$

and the initial condition

$$
u(x, t=0)=f(x)=18.67(0.03-x)-5.2,
$$

which is easily retrieved from the temperature data in the steady state regime. It gives indeed $T_{S}(0)=-4.64^{\circ} \mathrm{C}$ at the ice surface and $T_{I}(0)=-5.2^{\circ} \mathrm{C}$ at the ice/concrete interface, as in Fig.11.

The boundary conditions are in general given by the measurements. In this specific case, $T_{S}(t)$ is computed at the ice surface (at the water/ice interface) and $T_{I}(t)$ at the ice/concrete interface. They both are illustrated in Fig.3.

To obtain the analytical form of $T_{S}(t)$, we interpolate the temperature of the ice pad at the surface. The overall trend, including the entire curve from the beginning of resurfacing to $t=620 \mathrm{~s}$, is clearly logarithmic. It gives the equation

$$
T_{S}(t)=-0.641 \ln (t)+0.4016 \quad t[s] \leq 620 .
$$

If instead we consider e.g. only the first minute, the surface temperature becomes

$$
T_{S}(t)=2 \times 10^{-5} t^{3}-0.0015 t^{2}-0.0065 t-1.0633, \quad t[s] \leq 60 .
$$

These interpolations are given in Figs. 9 and 10. The temperature raise in the last $10 \mathrm{~s}$ is due to the third order polynomial (this is non physical, still it remains within the experimental error and does not affect the result sensibly). The formula for the iceconcrete interface temperature, in the first approximation, is also a simple third-order polynomial obtained from the field measurements (Fig.3),

$$
T_{I}(t)=6 \times 10^{-6} t^{3}-3 \times 10^{-4} t^{2}+4.3 \times 10^{-3} t-5.2071,
$$

which is plotted in Fig.12. We will apply these in the Appendix.

To solve the Cauchy problem given by Eqs.(35), (36), (37) and (38), we adopt the method of Eigenfunctions Expansions detailed in Titchmarsh (1962a,b); Hahn and 


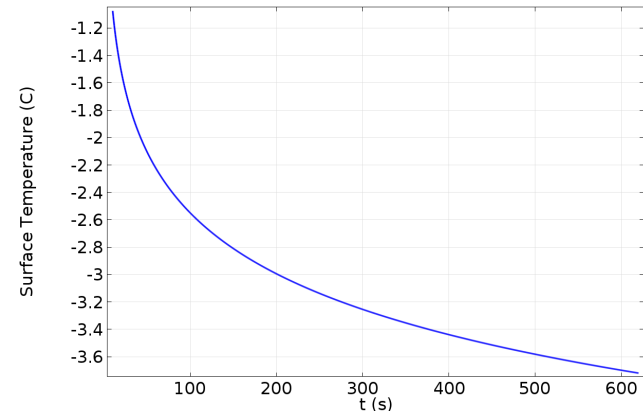

Figure 9. Interpolation of the surface temperature $T_{S}(t)$ over $t \leq 620 \mathrm{~s}$.

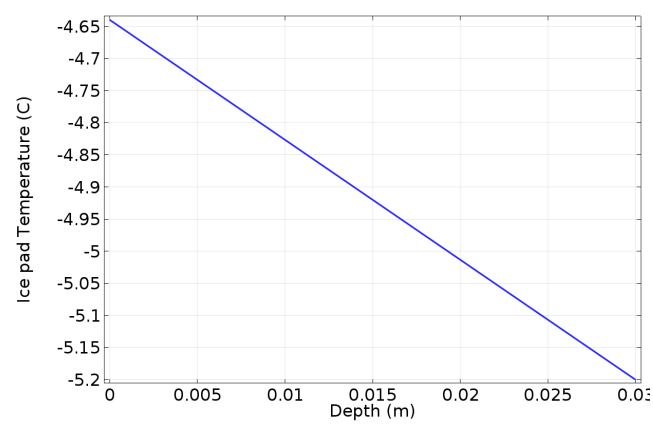

Figure 11. Initial condition $f(x)$.

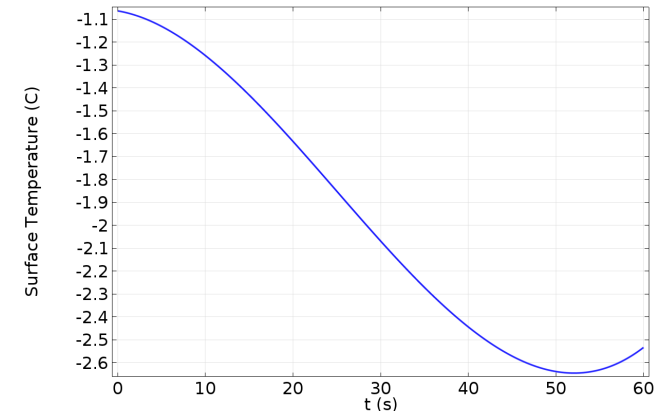

Figure 10. Interpolation of the surface temperature $T_{S}(t)$ for $t<60 s$.

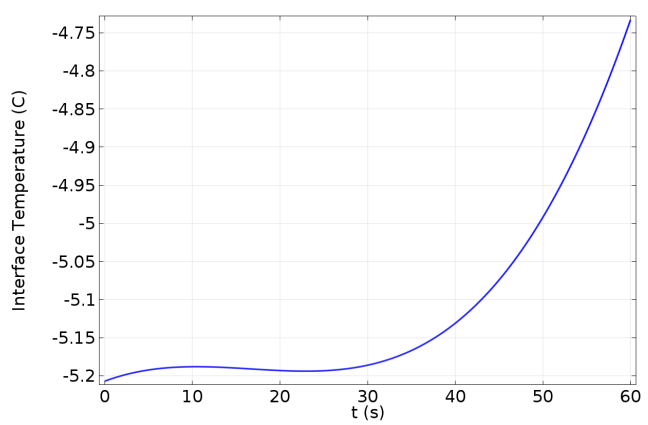

Figure 12. Interpolation of the interface temperature $T_{I}(t)$ for $t<60 \mathrm{~s}$.

Ozisik (2012) as follows. First impose the following Ansatz

$$
w(x, t)=T_{S}(t)+x\left(\frac{T_{I}(t)-T_{S}(t)}{L}\right),
$$

that implies

$$
\begin{aligned}
& w(0, t)=T_{S}(t), \\
& w(L, t)=T_{I}(t) .
\end{aligned}
$$

Now define the temperature profile $u(x, t)$ as the sum

$$
u(x, t)=w(x, t)+v(x, t),
$$

and substitute this expression in the Cauchy problem. We obtain

$$
v_{t}=\alpha_{I} v_{x x}-w_{t},
$$

where we have simplified the derivatives notation, with the Dirichlet boundary conditions $v(0, t)=v(L, t)=0$ and the initial condition $v(x, 0)=f(x)-w(x, 0)$. Now use 
the Eigenfunction expansion

$$
v(x, t)=\sum_{n=1}^{\infty} \hat{v}_{n}(t) \sin \left(\lambda_{n} x\right)
$$

to separate space and time dependence. The eigenvalues and eigenfunctions associated to the Dirichlet b.c. are

$$
\begin{aligned}
& \lambda_{n}=\left(\frac{n \pi}{L}\right), \quad n \in \mathbb{N} ; \quad X_{n}(x)=\sin \left(\lambda_{n} x\right) \\
& S(x, t)=-w_{t}=-\left(\dot{T}_{I}(t)-\dot{T}_{S}(t)\right)\left(\frac{x}{L}\right)-\dot{T}_{S}(t) .
\end{aligned}
$$

Therefore we obtain a first order linear ODE

$$
\frac{d \hat{v}_{n}}{d t}+\alpha_{I} \lambda_{n}^{2} \hat{v}_{n}=\hat{S}_{n}(t)
$$

where

$$
\begin{aligned}
\hat{S}_{n}(t) & =\frac{2}{L} \int_{0}^{L}\left[-\dot{T}_{S}(t)-\frac{x}{L}\left(\dot{T}_{I}(t)-\dot{T}_{S}(t)\right)\right] \sin \left(\frac{n \pi x}{L}\right) d x \\
& =\frac{2}{n \pi}\left[\left(\frac{\sin n \pi}{n \pi}-1\right) \dot{T}_{S}(t)-\left(\frac{\sin n \pi}{n \pi}-\cos n \pi\right) \dot{T}_{I}(t)\right]
\end{aligned}
$$

with an integrating factor $F(t)=e^{\alpha_{I} \lambda_{n}^{2} t}$. Eq. (50) can then be integrated to give the following solution,

$$
v(x, t)=\sum_{n=1}^{\infty}\left\{\int_{0}^{t} d \tau e^{-\alpha_{I} \lambda_{n}^{2}(t-\tau)} \hat{S}_{n}(\tau)+e^{-\alpha_{I} \lambda_{n}^{2} t} c_{n}\right\} \sin \left(\lambda_{n} x\right)
$$

where the coefficients

$$
c_{n}=\frac{2}{L} \int_{0}^{L}\left\{f(x)-\left[\left(T_{I}(0)-T_{S}(0)\right)\left(\frac{x}{L}\right)+T_{S}(0)\right]\right\} \sin \left(\frac{n \pi x}{L}\right) d x
$$

are given by the initial condition $u(0, x)=f(x)$.

Putting everything together, we can now write the analytical temperature profile for the ice pad Eq.(45) as

$$
\begin{aligned}
u(x, t) & =T_{i c e}(x, t)=\left[T_{I}(t)-T_{S}(t)\right]\left(\frac{x}{L}\right)+T_{S}(t) \\
& +\sum_{n=1}^{\infty}\left\{\int_{0}^{t} d \tau e^{-\alpha_{I} \lambda_{n}^{2}(t-\tau)} \hat{S}_{n}(\tau)+e^{-\alpha_{I} \lambda_{n}^{2} t} c_{n}\right\} \sin \left(\lambda_{n} x\right)
\end{aligned}
$$

that constitutes a novel result of this paper. This is a completely general formula, with implicit initial condition $f(x)$ and b.c. $T_{I}(t)$ and $T_{S}(t)$.

The above clearly reduces to the ice temperature $T_{S}(t)$ at the surface for $x=0$, while it is slightly less immediate to verify that (54) is consistent with the temperature 
at the bottom of the ice pad $T_{I}(t)$ for $x=L$. In this case we get

$$
\begin{aligned}
u(L, t) & =T_{i c e}(L, t) \equiv T_{I}(t)=\left[T_{I}(t)-T_{S}(t)\right]+T_{S}(t) \\
& +\sum_{n=1}^{\infty}\left\{\int_{0}^{t} d \tau e^{-\alpha_{I} \lambda_{n}^{2}(t-\tau)} \hat{S}_{n}(\tau)+e^{-\alpha_{I} \lambda_{n}^{2} t} c_{n}\right\} \sin \left(\lambda_{n} L\right) .
\end{aligned}
$$

Recall now that

$$
\lambda_{n}=\frac{n \pi}{L},
$$

which implies

$$
-2 T_{S}(t) \sum_{1}^{\infty} \frac{\sin \left(\lambda_{n} L\right)}{n \pi}=-2 T_{S}(t) \sum_{1}^{\infty} \frac{\sin n \pi}{n \pi}=0,
$$

since each term in the summation is identically zero. Regarding the term containing the integral,

$$
2 \sum_{1}^{\infty} \frac{\alpha_{I} \lambda_{n}^{2}}{n \pi} \sin \left(\lambda_{n} L\right) e^{-\alpha_{I} \lambda_{n}^{2} t} \int_{0}^{t} d \tau e^{\alpha_{I} \lambda_{n}^{2} \tau} T_{S}(\tau) \propto \sum_{1}^{\infty} n \sin n \pi e^{-\alpha_{I} \lambda_{n}^{2} t} \equiv 0,
$$

again because $\sin n \pi=0, \forall n \in \mathcal{N}$. So we get an identity $0=0$, as required.

Fisically, the terms in brackets in Eq.(54) give the transient state correction to temperature, that depends on the history of the process (via the $t$-integral) and on the initial and boundary conditions by virtue of Eqs.(51) and (53). This is plotted in Fig.A3 for our specific example calculated in the Appendix, where the initial condition (38) and the boundary conditions (40) and (41) pertain the resurfacing process.

The according analytical temperature profile (54) is given in Figure 13. In Fig.15 this is compared to a numerical solution by a Finite Element Model (FEM), which is plotted in Figure 14. Details of the analytical computation are discussed in the Appendix.

In conclusion, Eq. (54) provides a general formula for the temperature profile $T(x, t)$ at any point $x$ of the ice pad, at any generic time $t$ corresponding to any situation in the ice hockey hall (closing hours, resurfacing or skaters' activity). The practical problem of studying the complex physical processes over and under the ice pad is here avoided by virtue of the boundary conditions (i.e. experimental data), which encode all the involved phenomenology in a very simple analytical form.

\section{Conclusions}

In this paper we have considered thermophysical processes in an ice hockey arena during standard operation hours. Detailed heat flux, air and ice temperature and relative humidity data are provided and discussed in a quantitative analysis with specific focus on the maintenance (resurfacing) phase. The indoor air data provided constitute a stratification mapping at several heights from the ice rink, from $4 \mathrm{~cm}$ to $8 \mathrm{~m}$ above the ice, together with temperature and heat flux measurements at the ice/concrete interface. 
Outside the occupation hours, we find a strong temperature stratification in the air above the ice rink, which is compromised once the skaters start their activity. The effect of the ventilation system, delivering air at $25^{\circ} \mathrm{C}$ at about $5 \mathrm{~m}$ above the ice, is instead independent of the skaters, yet it is critically affecting the air layers temperature. As it is shown in Figure 6, our data read warmer air at $5 \mathrm{~m}$ than at $8 \mathrm{~m}$. Therefore one should control the ventilation system to avoid energy dissipation, and/or use waste energy techniques as in Lu et al. (2011); Lü et al. (2014).

An energy balance calculation shows the different contributions to the heat load on the ice rink, finding confirmation in the literature. The thermal radiation from the ceiling results to be the largest contribution (74\%), followed by lighting (14\%), with excellent agreement between our calculations and the temperature and heat flux measurements (this also constitutes a method for checking the data consistency). Together with the data measurements discussed in Section 2, such quantitative knowledge can aid energy saving efforts in a wide range of studies, since these processes occur in an average-sized ice hall under standard operating conditions.

Our measurements were then used to derive a direct analytical formula for the temperature inside the ice pad, viewed as a medium which is subject to conduction with time-dependent boundary conditions. When applied to the case at hand for validation, we showed that this is fairly consistent with a numerical computation for the ice pad temperature along its thickness, and that it reproduces the initial ice pad temperature profile correctly. Our formula is general and structurally simple, thus it can be readily applied to a number of investigations not limited to ice hockey halls.

Furthermore, we adopted a bottom-up approach where all the physics is encoded in the boundary conditions, circumventing an otherwise involved phenomenological analysis. This article suggests therefore a methodology which is firmly grounded on experimental data, using induction to obtain theoretical (predictive) results, and deduction to apply these formulas and check the data consistency.

The accurate measurements, energy balance analysis and analytical temperature profile in the ice pad presented in this work can constitute useful tools for increasing the energy efficiency in the ice hockey arenas, since the ice thickness covers a role in the overall energy demand, as suggested by Somrani et al. (2008), and control of the indoor air stratification is capable of reducing the energy consumption appreciably, as demonstrated by Taebnia et al. (2019).

\section{Acknowledgements}

This paper is dedicated to the memory of Professor Martti Viljanen. The authors acknowledge financial support by TEKES, by the Estonian Research Council with Institutional research funding grant IUT1-15 and by the Estonian Centre of Excellence in Zero Energy and Resource Efficient Smart Buildings and Districts, ZEBE, grant 2014-2020.4.01.15-0016 funded by the European Regional Development Fund.

\section{Appendix A. Analytical temperature profile during resurfacing.}

The temperature profile (54) was obtained in Section 4 in implicit form. In this section we put it into context, by using the initial and boundary conditions Eqs.(38), (40) and (41) to obtain the temperature profile inside the ice pad during the resurfacing process. This constitutes also a validation of our formula, as the profile at $t=0$ s agrees with 
the measurements reported in Section 3. First, we expand Eq.(51),

$$
\begin{aligned}
\hat{S}_{n}(t) & =\frac{2}{n \pi}\left[\left(\frac{\sin n \pi}{n \pi}-1\right) \dot{T}_{S}(t)-\left(\frac{\sin n \pi}{n \pi}-\cos n \pi\right) \dot{T}_{I}(t)\right] \\
& =\frac{1}{n \pi}\left[\left(8.4 \frac{\sin n \pi}{n \pi}+3.6 \cos n \pi-12\right) \times 10^{-5} t^{2}\right. \\
& +\left(-0.0048 \frac{\sin n \pi}{n \pi}-0.0012 \cos n \pi+0.006\right) t \\
& \left.+\left(-0.0261 \frac{\sin n \pi}{n \pi}+0.0086 \cos n \pi+0.013\right)\right],
\end{aligned}
$$

then the coefficients (53),

$$
\begin{aligned}
c_{n} & =\frac{2}{L} \int_{0}^{L}\left\{f(x)-\left[\left(T_{I}(0)-T_{S}(0)\right)\left(\frac{x}{L}\right)+T_{S}(0)\right]\right\} \sin \left(\frac{n \pi x}{L}\right) d x \\
& \sim \frac{1}{n \pi}\left[7.167\left(\frac{\sin n \pi}{n \pi}-1\right)-0.0142 \cos n \pi\right]
\end{aligned}
$$

because $0.998 \sim 1$. Already at this stage we notice the suppression factor $1 / n$. The integral in Eq.(54) is now computed as

$$
\begin{aligned}
& I_{n}(t) \equiv \int_{0}^{t} d \tau e^{-\alpha_{I} \lambda_{n}^{2}(t-\tau)} \hat{S}_{n}(\tau)= \\
& =\frac{1}{n^{3}}\left\{( e ^ { - 0 . 0 1 3 2 7 n ^ { 2 } t } - 1 ) \left[\left(0.1649-\frac{2.762}{n^{2}}-\frac{7.284}{n^{4}}\right) \frac{\sin n \pi}{n}\right.\right. \\
& \left.-\left(0.206+\frac{2.169}{n^{2}}+\frac{9.808}{n^{4}}\right) \cos n \pi-0.312+\frac{10.846}{n^{2}}+\frac{32.693}{n^{4}}\right] \\
& +\left(0.00064 \frac{\sin n \pi}{n}+0.00086 \cos n \pi-0.0029\right) t^{2} \\
& \left.-\left[\left(0.037+\frac{0.097}{n^{2}}\right) \frac{\sin n \pi}{n}+\left(0.029+\frac{0.13}{n^{2}}\right) \cos n \pi-0.144-\frac{0.434}{n^{2}}\right] t\right\}
\end{aligned}
$$

since $e^{\alpha_{I} \lambda_{n}^{2} \tau}=e^{0.01327 n^{2} t}$. We can thus recast the overall summation as

$$
\begin{aligned}
& \sum_{n=1}^{\infty}\left\{\int_{0}^{t} d \tau e^{-\alpha_{I} \lambda_{n}^{2}(t-\tau)} \hat{S}_{n}(\tau)+e^{-\alpha_{I} \lambda_{n}^{2} t} c_{n}\right\} \sin \left(\lambda_{n} x\right) \\
& =\sum_{n=1}^{\infty}\left\{I_{n}(t)+\frac{e^{-0.01327 n^{2} t}}{n}\left(0.73 \frac{\sin n \pi}{n}-0.01 \cos n \pi-2.28\right)\right\} \sin \frac{n \pi}{L} x
\end{aligned}
$$

which is clearly convergent, since everything is proportional to $\propto 1 / n^{a}$. 
The first 30 terms in the summation at $t=30 \mathrm{~s}$ are plotted separately in Fig.A1; we see that only the first six or seven matter significantly. The largest contribution, for $n=1$, is shown in Fig.A2, where the correction to the temperature (in absolute value) is maximal at $t=0 s$ and minimal at $t \sim 50 s$.

The temperature profile inside the ice pad Eq.(54) is accordingly rewritten as follows,

$$
\begin{aligned}
u(x, t)= & T_{i c e}(x, t)=\left[T_{I}(t)-T_{S}(t)\right]\left(\frac{x}{L}\right)+T_{S}(t) \\
+ & \sum_{n=1}^{\infty}\left\{\int_{0}^{t} d \tau e^{-\alpha_{I} \lambda_{n}^{2}(t-\tau)} \hat{S}_{n}(\tau)+e^{-\alpha_{I} \lambda_{n}^{2} t} c_{n}\right\} \sin \left(\lambda_{n} x\right) \\
= & -\left(1.4 \times 10^{-5} t^{3}-0.0012 t^{2}-0.0108 t+4.1438\right) \frac{x}{L} \\
& +2 \times 10^{-5} t^{3}-0.0015 t^{2}-0.0065 t-1.0633 \\
+ & \sum_{n=1}^{\infty}\left\{\int_{0}^{t} d \tau e^{-\alpha_{I} \lambda_{n}^{2}(t-\tau)} \hat{S}_{n}(\tau)+e^{-\alpha_{I} \lambda_{n}^{2} t} c_{n}\right\} \sin \left(\lambda_{n} x\right),
\end{aligned}
$$

where the temperature correction generated by the summation is computed with (A3) and (A4); it is shown in Figure A3 after 30s, where the first 100 terms are summed. Figure 15 compares the analytical solution (A5) to an FEM calculation for $t=30 \mathrm{~s}$, with $n=1 \ldots 100$. We notice a good agreement between the two curves.

We remark that this result is specifically valid for any $t \leq 60 \mathrm{~s}$, since the boundary conditions $T_{S}(t)$ and $T_{I}(t)$ are interpolations corresponding only to such time interval. Choosing different times will change the explicit form of both $T_{S}(t)$ and $T_{I}(t)$. On the contrary, the temperature profile Eq.(54) found in Section 4 is given with implicit initial and boundary conditions, which makes it general and applicable to a range of diverse engineering problems.

\section{References}

ASHRAE (1994). Refrigeration. Systems and Applications. Technical report, American Society of Heating, Refrigeration and Air-Conditioning Engineers.

ASHRAE (2010). Refrigeration. Systems and Applications. Technical report, American Society of Heating, Refrigeration and Air-Conditioning Engineers.

Bellache, O., Ouzzane, M., and Galanis, N. (2005). Numerical prediction of ventilation patterns and thermal processes in ice rinks. Building and Environment, 40(3), 417 -426 .

Bellache, O., Galanis, N., Ouzzane, M., Sunyé, R., and Giguère, D. (2006). Twodimensional transient model of airflow and heat transfer in ice rinks. ASHRAE Transactions, $\mathbf{1 1 2}(2), 706-716$.

Caliskan, H. and Hepbasli, A. (2010). Energy and exergy analyses of ice rink buildings at varying reference temperatures. Energy and Buildings, 42(9), $1418-1425$.

Daoud, A., Galanis, N., and Bellache, O. (2008). Calculation of refrigeration loads by convection, radiation and condensation in ice rinks using a transient $3 \mathrm{~d}$ zonal model. Applied Thermal Engineering, 28(14-15), 1782 - 1790.

Erol, G. O., Açıkkalp, E., and Hepbasli, A. (2017). Performance assessment of an ice rink refrigeration system through advanced exergoeconomic analysis method. Energy and Buildings, 138, $118-126$.

Ferrantelli, A., Mélois, P., Räikkönen, M., and Viljanen, M. (2013). Energy op- 
timization in ice hockey halls I. the system COP as a multivariable function, brine and design choices. In Sustainable Building Conference sb13 munich, Implementing Sustainability - Barriers and Chances. Fraunhofer IRB Verlag. e-arxiv: http://arxiv.org/abs/1211.3685.

Granryd, E. (2005). Refrigerating Engineering, Part II. KTH, Department of Energy Technology.

Haghighi, E. B., Makhnatch, P., and Rogstam, J. (2014). Energy saving potential with improved concrete in ice rink floor designs. International Journal of Civil, Environmental, Structural, Construction and Architectural Engineering, 8(6), 635 641.

Hahn, D. W. and Ozisik, M. N. (2012). Heat Conduction. John Wiley, 3rd edition.

Hastaoglu, M. A., Negiz, A., and Heidemann, R. A. (1995). Three-dimensional transient heat transfer from a buried pipe Part III. Comprehensive model. Chemical Engineering Science, 50(16), 2545 - 2555.

Karampour, M. (2011). Measurement and modeling of ice rink heat loads. Master's thesis, Royal Institute Of Technology, Stockholm, Sweden.

Krarti, M. (1999). Building foundation heat transfer. BIOPROCESS TECHNOLOGY, 13, 241-316.

Lu, T., Lü, X., Remes, M., and Viljanen, M. (2011). Investigation of air management and energy performance in a data center in Finland: Case study. Energy and Buildings, 43(12), 3360 - 3372 .

Lü, X., Lu, T., Kibert, C. J., and Viljanen, M. (2014). A novel dynamic modeling approach for predicting building energy performance. Applied Energy, 114(0), 91 103.

Lü, X., Lu, T., Kibert, C. J., and Viljanen, M. (2015). Modeling and forecasting energy consumption for heterogeneous buildings using a physical-statistical approach. Applied Energy, 144(0), 261 - 275.

Mun, J. and Krarti, M. (2011). An ice rink floor thermal model suitable for wholebuilding energy simulation analysis. Building and Environment, 46(5), 1087 - 1093.

Negiz, A., Hastaoglu, M. A., and Heidemann, R. A. (1993). Three-dimensional transient heat transfer from a buried pipe I. Laminar flow. Chemical Engineering Science, 48(20), 3507 - 3517.

Omri, M., Barrau, J., Moreau, S., and Galanis, N. (2016). Three-dimensional transient heat transfer and airflow in an indoor ice rink with radiant heat sources. Building Simulation, 9(2), 175-182.

Osram GmbH (2014). Osram POWERSTARß HQIR - Technical Information. Technical report, Osram.

Palmowska, A. and Lipska, B. (2018). Research on improving thermal and humidity conditions in a ventilated ice rink arena using a validated cfd model. International Journal of Refrigeration, 86, 373 - 387.

Poirier, L., Lozowski, E. P., and Thompson, R. I. (2011). Ice hardness in winter sports. Cold Regions Science and Technology, 67(3), 129 - 134.

Räikkönen, M. (2012). Jäähallin energiatehokkuus. Diploma thesis, Aalto University.

Seghouani, L., Daoud, A., and Galanis, N. (2009). Prediction of yearly energy requirements of indoor ice rinks. Energy and Buildings, 41(5), $500-511$.

Seghouani, L., Daoud, A., and Galanis, N. (2011). Yearly simulation of the interaction between an ice rink and its refrigeration system: A case study. International Journal of Refrigeration, 34(1), 383 - 389 .

Somrani, R., Mun, J., and Krarti, M. (2008). Heat transfer beneath ice-rink floors. Building and Environment, 43(10), 1687 - 1698. 
Taebnia, M., Toomla, S., Leppä, L., and Kurnitski, J. (2019). Air distribution and air handling unit configuration effects on energy performance in an air-heated ice rink arena. Energies, $\mathbf{1 2}(4)$.

Teyssedou, G., Zmeureanu, R., and Giguere, D. (2009). Thermal response of the concrete slab of an indoor ice rink (RP-1289). Technical report, HVAC \& R Research. Taylor \& Francis Ltd.

Teyssedou, G., Zmeureanu, R., and Giguere, D. (2013). Benchmarking model for the ongoing commissioning of the refrigeration systemof an indoor ice rink. Automation in Construction, 35(0), 229 - 237.

Titchmarsh, E. (1962a). Eigenfunction Expansions part 1. Oxford University Press (Clarendon Press).

Titchmarsh, E. (1962b). Eigenfunction Expansions part 2. Oxford University Press (Clarendon Press).

Toomla, S., Lestinen, S., Kilpeläinen, S., Leppä, L., Kosonen, R., and Kurnitski, J. (2018). Experimental investigation of air distribution and ventilation efficiency in an ice rink arena. International Journal of Ventilation, pages 1-17.

Tutumlu, H., Yumrutaş, R., and Yildirim, M. (2018). Investigating thermal performance of an ice rink cooling system with an underground thermal storage tank. Energy Exploration 83 Exploitation, 36(2), 314-334.

Yang, C., Demokritou, P., Chen, Q., Spengler, J., and Parsons, A. (2000). Ventilation and air quality in indoor ice skating arenas. ASHRAE Transactions, 106(2), 338346.

Yang, C., Demokritou, P., Chen, Q., and Spengler, J. (2001). Experimental validation of a computational fluid dynamics model for IAQ applications in ice rink arenas. Indoor Air, 11(2), 120-126. 


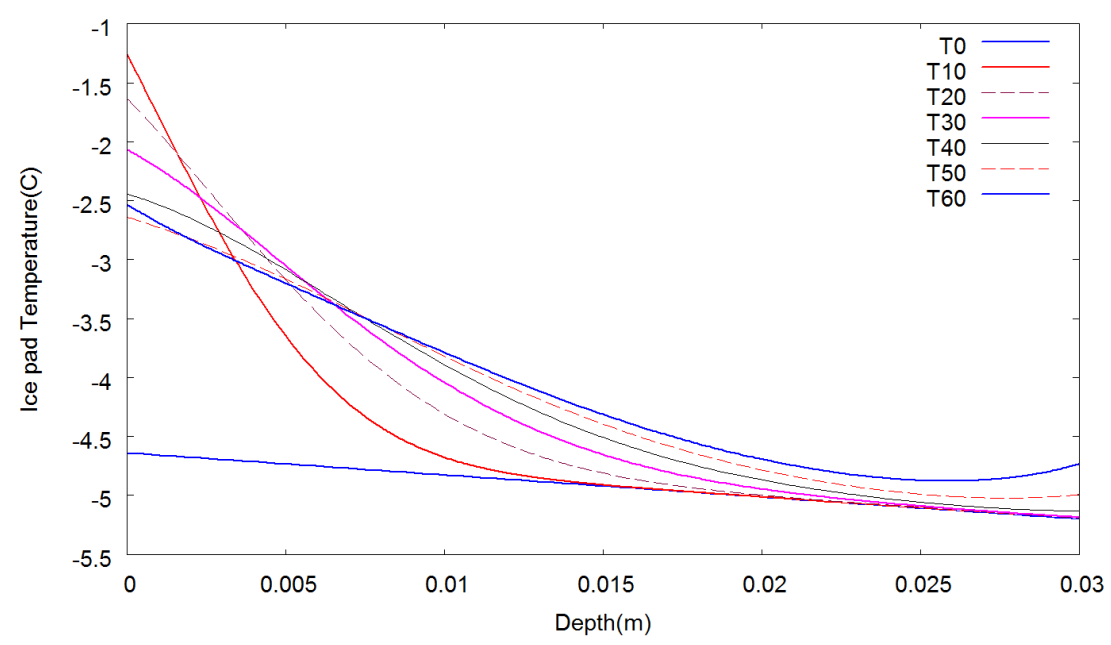

Figure 13. Temperature profile in the ice pad, analytical solution.

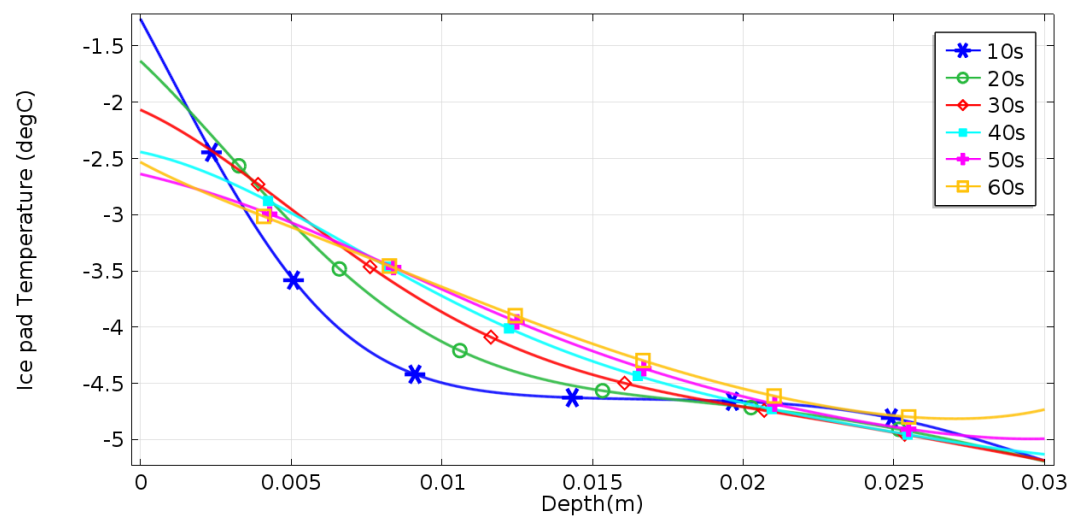

Figure 14. FEM solution for $t=0 \ldots 60 s$.

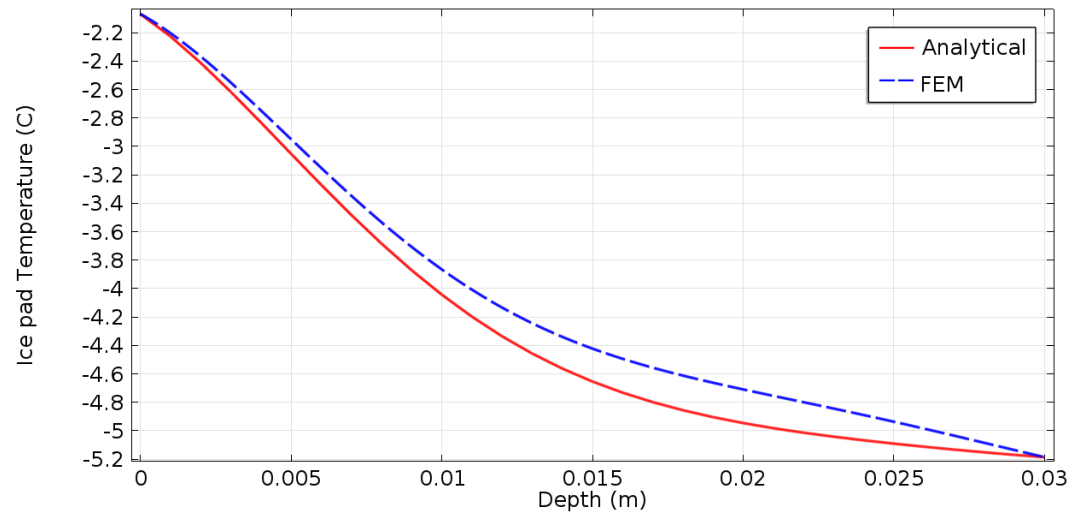

Figure 15. Temperature profile after $t=30 \mathrm{~s}$, analytical (solid) versus FEM (dashed). 


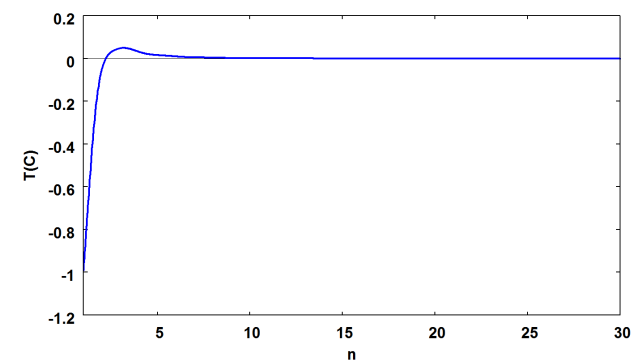

Figure A1. Contribution of the first 30 terms in the summation (A4), at $t=30 \mathrm{~s}$.

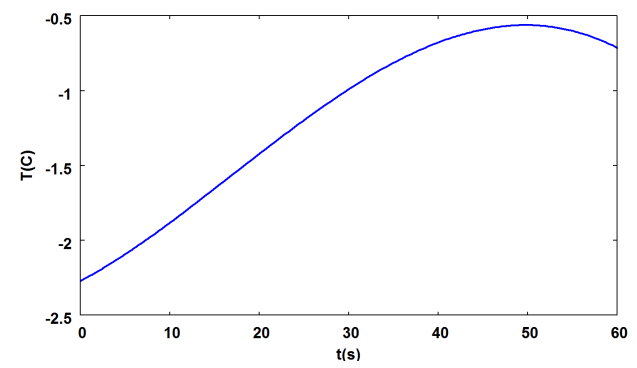

Figure A2. Largest $(n=1)$ contribution, where $0<t<60 s$.

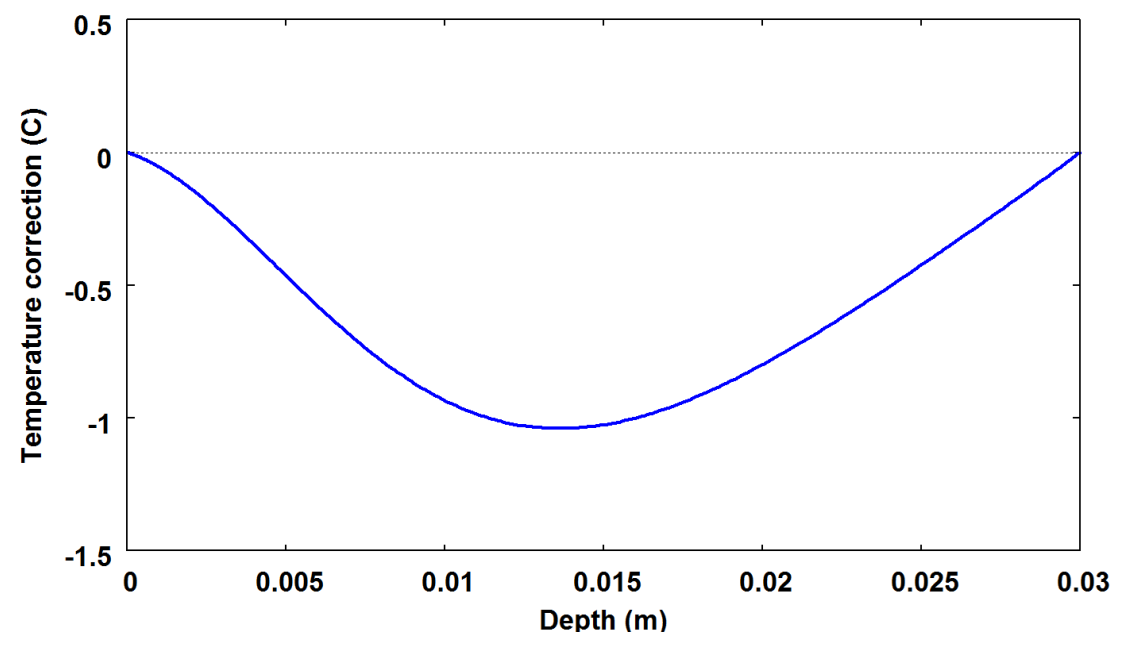

Figure A3. Temperature correction at $t=30 s$ with $n=1 \ldots 100$ in Eq.(A4). 